Buishand, T. A. \& C. A. Velds, 1980. Neerslag en verdamping. Royal Dutch Meteorological Institute, De Bilt.

Kraijenhoff, D. A., 1963. Areal distribution of extreme summer rainfall in the Netherlands. Mimeograph, Department of Hydraulics and Catchment Hydrology, Agricultural University, Wageningen.

Lowry, W. P., 1977. Empirical estimation of urban effects on climate: a problem analysis. Journal of Applied Meteorology 16: 129-135.

Matheron, G., 1971. The theory of regionalized variables and its applications. Ecole Nationale Supérieure des Mines de Paris, Paris.

NERC, 1975. Flood studies report, 5 vols. Natural Environment Research Council, London.

Rodríguez-Iturbe, I. \& J. M. Mejía, 1974. On the transformation of point rainfall to areal rainfall. Water Resources Research 10: 729-736.

USWB, 1957-1960. Rainfall intensity-frequency regime, 5 vols. US Department of Commerce, Washington, D.C.

This synopsis is based on a doctoral thesis, Agricultural University, Wageningen, 1984. ix +204 pp., 56 figs., 36 tables, 113 refs., appendices.

Available as paper copy (order R031P, $f 40$ including postage) or on microfiches (order R031M, f22.50 including postage) at: NARD, clo Pudoc, P.O. Box 4, 6700 AA Wageningen, Netherlands (telex 45015 blhwg $\mathrm{nl}$ ).

\title{
Impact of medium-sized wind turbines on birds: a survey on flight behaviour, victims, and disturbance
}

J. E. Winkelman (Research Institute for Nature Management, P.O. Box 9201, 6800 HB Arnhem, Netherlands)

Received 25 January 1985; accepted 27 February 1985

\begin{abstract}
In the autumn and winter of 1983/1984, a study was made on the possible danger of medium-sized wind turbines (tower height 10-30 m, rotor diameter 7-25 m, power $50-300 \mathrm{~kW}$ ) to birds. The main points studied were flight behaviour of birds approaching turbines in daylight, and number of birds killed at night. Some attention was paid to possible loss of breeding and feeding habitat around present sites of turbines.

Key-words: birds, wind turbine, flight behaviour, collision, ecological disturbance, bird mortality.
\end{abstract}

Introduction. Although wind power exploited by wind turbines is thought to be rather harmless to the environment, a possible danger could be the impact on birds (Avery et al., 1976; Bleijenberg \& Feenstra, 1982; Karlsson, 1977). Little has yet been published to support this opinion. So the Dutch National Development Pro- 
gram for Wind Energy, which strives after 15000 medium-sized and 1000 large wind turbines scattered over the country in the year 2000, supported a study on the impact of medium-sized wind turbines on birds.

Material and methods. During the autumn, responses of diurnal migrants were studied at five sites along the Dutch coast. Responses of local birds flying to and from their roosting and feeding areas were observed at the same coastal sites and at one site further inland. Observations were made on birds approaching within 200-300 m distance of the turbines (a single one at 4 sites, a group of 2 or 4 in line at one site each). All records were made in daylight in fine weather (good visibility). Recorded were species, age (gulls) and numer of birds, height, distance and direction of flight both when approaching the turbine, and during and after a possible response, and weather data.

Almost daily, searches for turbine-killed birds were made early in the morning.

To estimate the possible loss or deterioration of breeding and feeding habitat, 60 sites with medium-sized turbines all over the country were visited to describe environment and (expected) bird-life.

\section{Results}

1. Flight behaviour. During 340 hours of observation, 87000 birds in 6200 flocks were recorded within $200-300 \mathrm{~m}$ of the turbines. Only 561 flocks $(7-19 \%$, on average $13 \%$, of migrating flocks and $4-6 \%$, on average $5 \%$, of local flights) showed a change in flight behaviour that could be attributed to the turbines. No collisions with the turbines were seen. Most responses $(97 \%)$ were a temporary evasion of the entire turbine, $3 \%$ came within reach of the rotor. A possible panic reaction was noted in $1 \%$ of the flocks. The majority (78-99\%) of the flocks avoided the obstacles by shifting their flight paths to the side (most often by $16-45^{\circ}$ ), mainly staying at the same height. Within the observed field, $21-37 \%$ of the diurnal migrants returned to the original track after reaction, none of the local birds.

The proportion of birds showing a response is influenced by several factors. Of the factors investigated, the following influenced the extent of hindrance:

- type of bird movement (migration or local flights): see flight behaviour

- action of turbine (operating or not): for diurnal migrants $11 \%$ and $5 \%$ response, respectively; no differences for local flights (both $5 \%$ ), suggestive of habituation of local birds to wind turbines

- site: when operating, turbines in line formation or the presence of buildings caused more response than solitary ones (no differences for still rotor)

- bird species: for operating turbines within 12 species groups (diurnal migration), least response (2-6\%) was found for waders, thrushes, and corvids, most response $(43 \%)$ for ducks and geese; other groups were intermediate, the extent of reaction varying with the site

- time of day: for operating turbines, there seemed to be a decrease in the response as down progressed and an increase during sunset (no differences in influence for still rotor) 
- flight height: for operating turbines, diurnal migrants showed most response at the height of the rotor and at $0-50 \mathrm{~m}$ above the top, followed by the class beneath the rotor ( $3 \mathrm{~m}$ to bottom of rotor) (no differences in influence for diurnal migration with still rotor, and for local flights)

- flight distance: for operating turbines, more response was found near the turbine than at greater distances; at 200-300 m, the response was also greater (for still rotor, no difference in influence); non-operating turbines seemed to be approached closer by birds than operating ones

- wind force: with increasing wind force, diurnal migrants seemed to respond more often

- wind direction: with operating rotor, diurnal migrants seemed to respond less often with tail winds than with side or head winds (no differences in influence for nonoperating turbines, and for local flights).

Flock size and age of birds did not seem to influence the response. The correlation between factors was not analysed. Other factors such as visibility of turbine, presence of flaps, downwind wake of the turbine, sound levels, and rotor speed were not examined.

Interfering elements (e.g. buildings) near the turbine were only indirectly studied. Observations were not always equal for the entire field of observation; there was also a parallax problem.

2. Victims. No dead birds were found at the base of the wind turbines. This result confirms the scarce data from the literature, but is difficult to interpret because of lack of data on removal of killed birds by scavengers, and lack of data on migration extent at low altitudes during the study period.

3. Loss of breeding and feeding habitat. Nearly all present sites of turbines are near other interfering elements, so it can be presumed that the effect of turbines on breeding and feeding habitat of birds has been negligible.

Discussion. The chance of collisions of birds with medium-sized turbines in daylight and in weather with good visibility is almost zero. At present sites, the disturbing effect of medium-sized turbines hardly interferes with feeding and breeding birds, if at all.

The results do not indicate (a) the danger of collisions at night or in daylight during weather with poor visibility, (b) the hindrance caused by other types of turbines (particularly large ones) and by large groups of wind turbines (e.g. wind parks), and (c) the risk at sites other than those studied. Based on the records of obstacles comparable to (large) wind turbines, collisions are only likely at night or with poor visibility, and are always incidental. Studies on the flight behaviour and height of flight during such circumstances are necessary.

\section{References}

Avery, M., P. F. Springer \& J. F. Cassel, 1976. The effects of a tall tower on nocturnal bird migration a portable ceilometer study. $A u k$ 93: 281-291.

Bleijenberg, A. N. \& J. J. Feenstra, 1982. Voorstellen onderzoek vogelhinder door windturbines. (Report.) Centrum voor Energiebesparing, Delft.

Karlsson, J., 1977. Fågelkollisioner med master och andra byggnadsverk. Anser 16: 203-216. 
This synopsis is based on a report entitled 'Vogelhinder door middelgrote windturbines', Report 84/7, Research Institute for Nature Management, Arnhem, 1984. 113 pp., 16 figs., 12 tables, 52 refs., 16 appendices. Dutch, English summary.

Available as paper copy (order R032P, $f 17.50$ including postage) or on microfiche (order R032M, f 17.50 including postage) at: NARD, clo Pudoc, P.O. Box 4, 6700 AA Wageningen, Netherlands (telex 450515 blhwg $\mathrm{nl}$ ).

\title{
Behaviour and biological impact of (un)treated oil spills in estuarine areas
}

M. J. N. Bergman (Research Institute for Nature Management, Department of Estuarine Ecology, P.O. Box 59, 1790 AB Den Burg Texel, Netherlands)

Received 30 November 1984; accepted 6 March 1985

\begin{abstract}
The purpose of this study was to prepare recommendations for optimal nature management of the biologically rich Dutch estuarine coastal areas in case of an oil spill.

Key-words: estuaries, oil pollution, biological impact, clean-up methods.

Introduction. In recent years several large oil spills have occurred. Extensive literature on the impact and combat has since been published (Baker, 1976; McCarthy, Lindblom \& Walter, 1978). Especially in estuarine areas biological effects seemed severe, and the need was felt to compile a review of available literature in order to advice the managing authorities in case of oil spills threatening Dutch estuarine areas.
\end{abstract}

Methods. Hundreds of articles, dealing with fate and effects of (treated) oil were studied, using bibliographies, special reports about oil spills and articles on oil experiments in the field situation, in outdoor model ecosystems and in the laboratory. The compiled knowledge about behaviour and impact of oil in estuaries is translated into the specific situation of estuarine coastal areas in the Netherlands of which the Wadden Sea is the most important one.

\section{Conclusions}

Fate of oil. After its introduction in the Wadden Sea oil will occur as a floating film, varying in thickness from some $\mu \mathrm{m}$ to a few $\mathrm{cm}$ (in case of mousse formation). In the absence of mousse up to $40 \%$ of a light crude oil may evaporate within 48 hours. Oil 